\title{
Bilateral pulmonary arteriovenous fistulae treated with balloon embolization
}

\author{
Satish Kumar,* Michael J. Ruttley and David J. Fisher \\ University of Wales College of Medicine, Royal Infirmary, Cardiff, Wales, UK.
}

\begin{abstract}
Summary: A patient with bilateral pulmonary arteriovenous fistulae is described who was treated successfully by embolization of the two fistulae with detachable balloons introduced percutaneously through the femoral vein.
\end{abstract}

\section{Introduction}

Congenital pulmonary arteriovenous fistulae can be single or multiple when they occur as part of the syndrome of hereditary haemorrhagic telangiectasia, (Dines et al., 1983). These fistulae are usually asymptomatic at birth but enlarge with age to become haemodynamically significant in adult life (Moyer et al., 1962). The right-to-left shunt causes systemic hypoxia which produces exertional dyspnoea and reduction in effort tolerance. Other dangerous complications are haemoptysis, paradoxical embolism and spontaneous rupture (Shumacker \& Waldhausen, 1963).

Conventional treatment of this condition has been surgical. This usually consists of lobectomy, segmentectomy or wedge resection - all of which involve loss of adjacent normal lung parenchyma. Pure fistulectomy was possible in only 9 out of 54 patients who underwent surgery for this condition at the Mayo Clinic between 1952 and 1981 (Dines et al., 1983).

Recently, these fistulae have been embolized percutaneously using coil devices (Taylor et al., 1978; Keller et al., 1984) or inflatable balloons (Barth et al., 1982; Rankin et al., 1983). We report a case of bilateral pulmonary fistulae treated successfully with repeated balloon embolization.

\section{Case report}

A 44 year old caucasian male was admitted in December 1983 with a 5 year history of exertional dyspnoea and proneness to easy fatigue. He also gave a 2 year history of chest pain suggestive of angina

*Correspondence and present address: S. Kumar, M.D., M.R.C.P., Department of Nephrology, University of Chicago, Box 453, 5841 S Maryland Avenue, Chicago-Il 60637, USA.

Accepted: 7 August 1985 pectoris. Hypertension had been discovered 15 years before admission when investigations had demonstrated absence of the left kidney with no renal artery on arteriography. He was taking clonidine and a thiazide-triamterene diuretic preparation for hypertension.

Physical examination revealed an obese man with central cyanosis and clubbing. Multiple telangiectasiae could be seen on the lips and face. Blood pressure was $160 / 100 \mathrm{mmHg}$. The liver was palpable $4 \mathrm{~cm}$ below the costal margin.

Investigations revealed haemoglobin of $17.8 \mathrm{~g} / \mathrm{dl}$. White cell count and platelet counts were normal. Liver function tests showed slightly raised liver enzymes only. Chest X-ray showed two 'tadpole' like lung opacities overlapping the left and right heart borders respectively (Figure 1). Spirometric lung func-

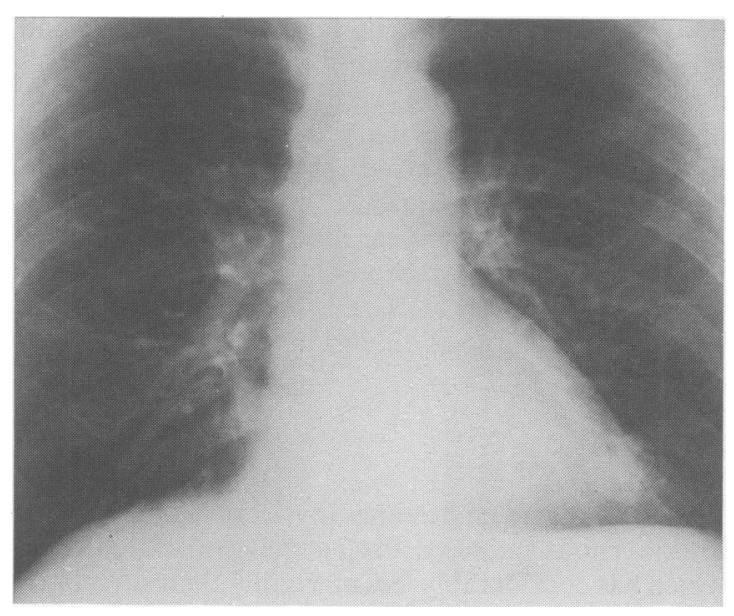

Figure 1 Chest X-ray showing the arteriovenous fistulae as 'tadpole' shaped opacities overlapping the left and right heart borders.

(C) The Fellowship of Postgraduate Medicine, 1986 
tion tests and diffusion capacity were normal. Supine arterial blood $\mathrm{PO}_{2}$ was $55 \mathrm{mmHg}$ (room air) and $115 \mathrm{mmHg}\left(100 \% \mathrm{O}_{2}\right)$; sitting and on room air the arterial $\mathrm{PO}_{2}$ was $46 \mathrm{mmHg}$.

Cardiac catheterization from the right femoral vein showed normal right heart and pulmonary pressures. Pulmonary arteriography confirmed the presence of two arteriovenous fistulae in the right middle and left lower lobes respectively, each with a single feeding artery and draining vein (Figure 2). The arteries measured $8 \mathrm{~mm}$ on the films and were considered suitable for embolization with the B-D MiniBalloon $^{\mathrm{TM}}$ detachable balloon system. A 6F Lehman catheter was placed in the feeding artery of the right middle lobe fistula and then exchanged over a $260 \mathrm{~cm}$ 'exchange' wire for an 8F Coronar FR4 catheter (Schneider Medintag AG - known to accept the miniballoon catheter and used in preference to the larger BD introducer catheter). The fistula was then occluded with the appropriate mini-balloon $(1.8 \mathrm{~mm}$ undistended, $8.7 \mathrm{~mm}$ distended diameter). The technique recommended by the manufacturer was modified by temporary proximal occlusion of the feeding artery with a Swan-Ganz balloon catheter (model 93-123-6F, Edwards Laboratories Inc., inserted through a right femoral vein sheath) during mini-balloon distension to minimize the risk of systemic embolization through the fistula from premature mini-balloon detachment, listed by the manufacturer as a possible complication in high flow lesions.

Following this first procedure, supine arterial $\mathrm{PO}_{2}$ rose to $74 \mathrm{mmHg}$ on room air and the patient reported improved effort tolerance. Four weeks later, the left lower lobe fistula was occluded by the same technique; arterial $\mathrm{PO}_{2}$ rose to $96 \mathrm{~mm} \mathrm{Hg}$ and there was further improvement in effort tolerance. One week later he developed left pleuritic chest pain and clinical and radiographic signs consistent with small basal pulmonary infarcts. These were attributed to balloon occlusion of small pulmonary arteries arising from the fistula artery; they resolved spontaneously and there were no other complications.

When last seen, one year after the first procedure, the patient was asymptomatic. Arterial $\mathrm{PO}_{2}$ was $80 \mathrm{mmHg}$ and a chest X-ray showed that both the balloons were in position and distended (Figure 3).

\section{Discussion}

Percutaneous embolotherapy of pulmonary arteriovenous fistulae is an effective form of treatment which has considerably less morbidity than surgery. It involves minimal loss of lung parenchyma and can be repeated if symptoms recur due to enlargement of previously small channels in a patient with multiple fistulae. Up to six balloons have been successfully

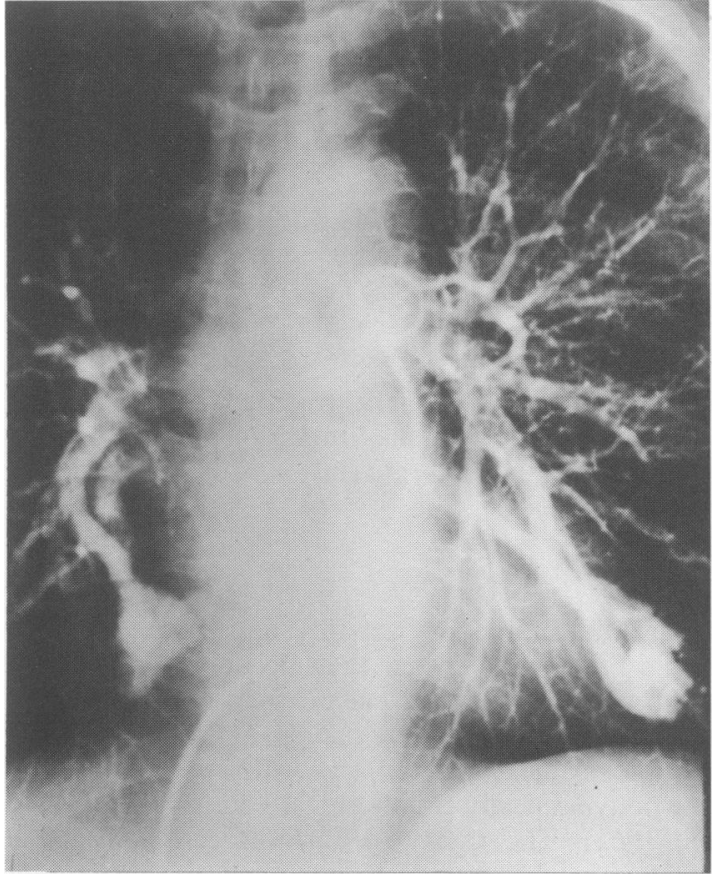

Figure 2 Pulmonary arteriogram showing the bilateral arteriovenous fistulae.

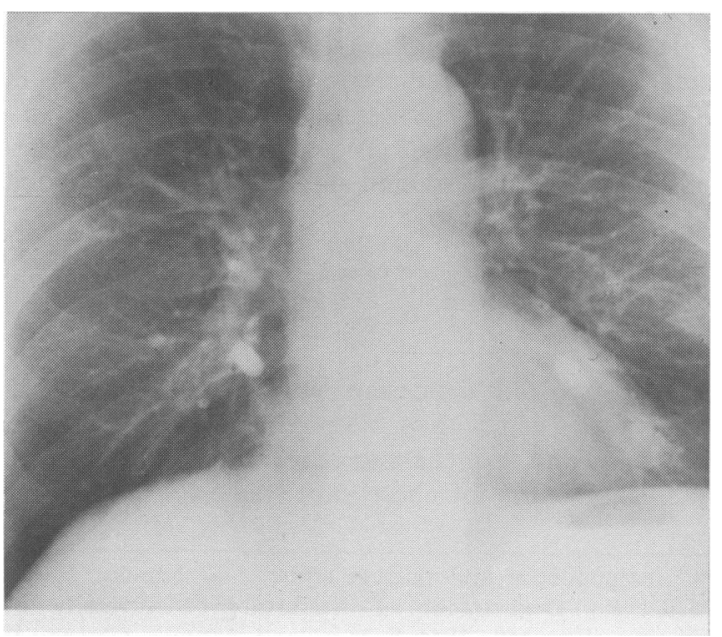

Figure 3 Chest X-ray showing distended balloons occluding each fistula. 
placed in a single patient (Barth et al., 1982).

The feeding artery of a fistula often provides branches to the adjacent normal lung and occlusion of such branches with consequent pulmonary infarction can complicate embolotherapy; such infarcts are usually minor, as in our patient, and, to our knowledge, no fatality has been recorded. The risk is minimized by using an embolic device which can be accurately positioned in the feeding artery distal to as many normal lung branches as possible.

Embolotherapy of pulmonary vessels has been tried successfully with coil devices (Taylor et al., 1978; Castaneda-Zuniga et al., 1980; Hatfield \& Fried, 1981; Keller et al., 1984) but they are more difficult to place accurately and unlike detachable balloons, allow no option of withdrawal if initially misplaced or incorrectly sized.

Systemic embolization has been reported as a complication of both coil and balloon occlusion of pulmonary arteriovenous fistulae (Barth et al., 1982). Balloon detachment prior to full distension must increase the risk of distal embolization through the fistula and such premature detachment is mentioned by the manufacturer as a known risk of B-D Mini-

\section{References}

BARTH, K.H., WHITE, R.I., KAUFMAN, S.I., TERRY, P.B. \& ROLAND, J.M. (1982). Embolotherapy of pulmonary arteriovenous malformations with detachable balloons. Radiology, 142, 599.

CASTANEDA-ZUNIGA, W., EPSTEIN, M., ZOLLIKOFER, C., NATH, P.H., FORMANEK, A., BEN-SHACHAR, G. \& AMPLATZ, K. (1980). Embolization of multiple pulmonary artery fistulas. Radiology, 134, 309.

DINES, D.E., ARMS, R.A., BERNATZ, P.E. \& GOMEZ, M.R. (1974). Pulmonary arteriovenous fistulas. Mayo Clinic Proceedings, 49, 460.

DINES, D.E., SEWARD, J.B. \& BERNATZ, P.E. (1983). Pulmonary arteriovenous fistulas. Mayo Clinic Proceedings, 58, 176.

HATFIELD, D.R. \& FRIED, A.M. (1981). Therapeutic embolization of diffuse pulmonary arteriovenous malformations. American Journal of Roentgenology, 137, 861.

KELLER, F.S., ROSCH, J., BARKER, A.F. \& NATH, P.H.(1984). Pulmonary arteriovenous fistulas occluded by percutaneous introduction of coil springs. Radiology, 152, 373.

MOYER, J.H., GLANTZ, G. \& BREST, A.N. (1962). Pulmonary
Balloon distension in high flow vessels where turbulence increases markedly as the balloon is distended. It seems reasonable to minimize this risk by a temporary occlusion of the feeding artery proximal to the distending balloon and this can easily be accomplished with the use of an additional non-detachable balloon catheter as described in our case.

Balloon occlusion is also suitable for patients with co-existent chronic obstructive airway disease who may be unfit for general anaesthesia. In such patients, measurement of orthodeoxia (desaturation in erect posture) is useful in determining the relative role of the two conditions in producing hypoxia (Robin et al., 1976). Since pulmonary arteriovenous fistulae are usually situated in the lower lobes (Dines et al., 1974) the shunt across them increases in the erect position, producing a fall in $\mathrm{PO}_{2}$ from supine to erect position. Hypoxia due to chronic obstructive airway disease, on the other hand, is worse in the supine position than sitting up (Streider et al., 1969).

We feel that balloon embolization of pulmonary arteriovenous fistulae is an effective alternative to surgery and should be the procedure of first choice in the management of this condition.

arteriovenous fistulas. American Journal of Medicine, 32, 417.

RANKIN, R.N., McKENZIE, F.N. \& AHMAD, D. (1983). Embolization of arteriovenous fistulas and aneurysms with detachable balloons. Canadian Journal of Surgery, 26, 317.

ROBIN, E.D., LAMAN, D., HORN, B.R. \& THEODORE, J. (1976). Platypnea related to orthodeoxia caused by true vascular lung shunts. New England Journal of Medicine, 294, 941.

SHUMACKER, H.B. JR. \& WALDHAUSEN, J.A. (1963). Pulmonary arteriovenous fistulas in children. Annals of Surgery, 158, 713.

STREIDER, D.J., MURPHY, R. \& KAZEMI, H. (1969). Mechanism of postural hypoxemia in asymptomatic smokers. American Review of Respiratory Disease, 99, 760.

TAYLOR, B.G., COCKERILL, E.M., MANFREDI, F. \& KLATTE; E.C. (1978). Therapeutic embolization of the pulmonary artery in pulmonary artriovenous fistula. American Journal of Medicine, 64, 360. 